\title{
Biochemical methane potential of microalgae biomass using different microbial inocula
}

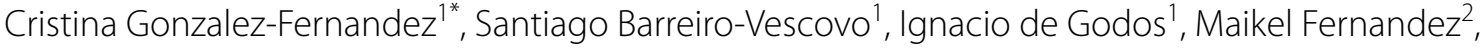 \\ Arbib Zouhayr ${ }^{2}$ and Mercedes Ballesteros ${ }^{1,3}$
}

\begin{abstract}
Background: Microalgae biomass is regarded as a potential feedstock for bioenergy purposes through anaerobic digestion (AD). Even though $\mathrm{AD}$ is a well-proven technology, the use of new feedstocks requires in-depth studies. A lot of research has been conducted assessing methane yield without paying attention to the anaerobic microbiome and their activities. For such a goal, the present investigation was designed to link methane yield to those two later sludge characteristics. In this sense, different anaerobic sources were tested, namely adapted to microalgae biomass and adapted to sewage sludge.

Results: Despite the registered differences for the anaerobic microbiome analysis and specific methane activities towards model substrates, sludge adapted to digest sewage sludge did not affect the methane yield of Chlorella sorokiniana and Scenedesmus sp. Opposite to that, sludge samples adapted to digest microalgae exhibited a concomitant increase in methane yield together with increasing digestion temperatures. More specifically, the values attained were $63.4 \pm 1.5,79.2 \pm 3.1$ and $108.2 \pm 1.9 \mathrm{~mL} \mathrm{CH}_{4} \mathrm{~g}$ COD in ${ }^{-1}$ for psychrophilic, mesophilic and thermophilic digestions, respectively. While psycro- and mesophilic digestion supported similar yields (most probably linked to their anaerobic microbiome resemblance), the values attained for thermophilic digestion evidenced the usefulness of having a highly specific microbiome. The relative abundance of Firmicutes, particularly Clostridia, and Proteobacteria together with an important abundance of hydrogenotrophic methanogens was highlighted in this inoculum.
\end{abstract}

Conclusion: Overall, this study showed that working with tailored anaerobic microbiome could help avoiding pretreatments devoted to methane yield enhancement.

Keywords: Microalgae, Anaerobic digestion, Anaerobic microbiome, Specific methanogenic activity, Inoculum

\section{Background}

Renewable energy will play a key role in limiting $\mathrm{CO}_{2}$ emissions while decreasing as well fossil fuel dependency. Renewable resources such as biomass and organic wastes are envisaged as promising feedstock for energy purposes. Anaerobic digestion is a proven technology for obtaining biogas via conversion of organic matter. In this regard, anaerobic digestion (AD) has been implemented in a large number of facilities and in fact, this number

\footnotetext{
*Correspondence: cristina.gonzalez@imdea.org

${ }^{1}$ Biotechnological Processes Unit, IMDEA Energy, Madrid, Spain

Full list of author information is available at the end of the article
}

increases over the years [1]. Facilities already running use mainly traditional feedstocks such as manure or energy crops (corn). However, the need of expanding AD to a range of new substrates has raised attention in key points that should be taken into account when new feedstocks are going to be used. Microalgae biomass has been the focus of interest in $\mathrm{AD}$ during the last decade. Microalgae biomass is a substrate of particular interest since it contributes to wastewater bioremediation and $\mathrm{CO}_{2}$ bio-mitigation. Additionally, microalgae biomass can be grown in non-arable land and are more productive than terrestrial plant due to their higher photosynthetic efficiency [2]. All 
these features render microalgae biomass as a promising feedstock for energy purposes.

Out of the different energy forms that can be produced using microalgae biomass as feedstock, biogas production via anaerobic digestion is probably the most economically feasible since it does not require highly concentrated biomass [3] and anaerobes can use the three biomass macromolecules (proteins, carbohydrates and lipids) for methane production purposes [4]. As a limiting step, anaerobic hydrolysis appears to be one of the most challenging steps to reach a positive economic balance and to completely exploit the potential of microalgae for biogas. Once evidenced the resilience of easily growing microalgae strains towards $\mathrm{AD}$, a great number of investigations have been devoted to pretreat this biomass prior to anaerobic digestion. A summary of the research efforts that have been undertaken to date can be found elsewhere [5, 6]. Several authors have found that the energy consumption associated to the pretreatment of microalgae biomass is equal to or higher than the energy gained $[7,8]$.

One alternative to the use of pretreatments is the selection of appropriate anaerobic inocula. In fact, it has been shown that the use of one or another inoculum influences the biochemical methane potential of different substrates [9-11]. A consortium of interdependent microorganisms composes the anaerobic inoculum. The prevalence of determined anaerobes might affect the hydrolytic and methanogenic activity of the sludge and thus, different microbial population might lead to different anaerobic digestion efficiencies. Moreover, not only the inherent microbial activity of the sludge might be of importance but this activity can also be tuned by microbial adaptation. Anaerobic microbial community has the ability to adapt to changing conditions. Microbial adaptation to the new situation entails most of the time a lower microorganism diversity but more specified [12]. In this manner, some of the adaptation mechanisms include genetic changes, selective population enrichment [13] and enzymatic activity modification [14].

Although a number of studies have addressed the limited anaerobic biodegradability of this biomass and potential pretreatment methods to enhance it, controversial results might be found in the literature dealing with microalgae biomass digestion. One of the reasons of different results has been attributed to the different anaerobic sludge inocula used in the digestions. In this sense, to the best of our knowledge, no investigation has been made on the effect of different anaerobic inocula in the methane yield achievable when using microalgae as substrates. As a matter of fact, when comparing different inocula, studies mostly focus on methane production or substrate degradation while inocula themselves are not paid enough attention. For this reason, the aim of this investigation was to evaluate the effect of different inoculum sources on microalgae biomass anaerobic digestion. Six different inocula were tested in terms of anaerobic microbiome, degradation activity towards model substrates and methane production yield using microalgae as feedstocks. Those inocula included four operating at mesophilic range $\left(35{ }^{\circ} \mathrm{C}\right.$ ), one psychrophilic (ambient temperature, $15-25{ }^{\circ} \mathrm{C}$ ) and one thermophilic $\left(55^{\circ} \mathrm{C}\right)$. Moreover, the psychro-, thermo- and one of the mesophilic sludge were adapted to digest microalgae biomass while the rest of them were adapted to sewage sludge degradation.

\section{Methods}

\section{Microalgae biomass used as substrate}

The substrate consisted in two types of microalgae biomass, namely Scenedesmus gender and the specie Chlorella sorokiniana. Scenedesmus inoculum was grown in synthetic media in $1 \mathrm{~L}$ flask under continuous artificial light supply (TL-D 36W, PHILIPS, Holland). Cultures were kept at room temperature $\left(22-24{ }^{\circ} \mathrm{C}\right)$ with magnetic stirring. Culture media consisted in (all compounds in $\mathrm{mg} \mathrm{L}^{-1}$ ): $160 \mathrm{NH}_{4} \mathrm{Cl}, 25 \mathrm{CaCl}_{2} \cdot 2 \mathrm{H}_{2} \mathrm{O}, 75 \mathrm{MgSO}_{4} \cdot 7 \mathrm{H}_{2} \mathrm{O}$, $75 \mathrm{~K}_{2} \mathrm{HPO}_{4}, 175 \mathrm{KH}_{2} \mathrm{PO}_{4}, 25 \mathrm{NaCl}, 50$ EDTA disodium, $31 \mathrm{KOH}, 4.98 \mathrm{FeSO}_{4} \cdot 7 \mathrm{H}_{2} \mathrm{O}, 11.42 \mathrm{H}_{3} \mathrm{BO}_{3}, 17.64$ $\mathrm{ZnSO}_{4} \cdot 7 \mathrm{H} 2 \mathrm{O}, 2.88 \mathrm{MnCl}_{2} \cdot 4 \mathrm{H}_{2} \mathrm{O}, 1.42 \mathrm{MoO}_{3}, 3.14$ $\mathrm{CuSO}_{4} \cdot 5 \mathrm{H}_{2} \mathrm{O}$, and $0.98 \mathrm{CoNO}_{3} \cdot 6 \mathrm{H}_{2} \mathrm{O}$.

Scenedesmus sp. was grown in a $200 \mathrm{~L}$ raceway reactor. The raceway was operated without temperature control $\left(20-24{ }^{\circ} \mathrm{C}\right)$ and the illumination consisted in 12 fluorescent lamps. Culture was conducted in semicontinuous condition; harvested and fed once per week. Fresh urban wastewater from Rey Juan Carlos University was used as culture media for Scenedesmus sp. The specific composition of the influent consisted in (all elements in $\mathrm{mg} \mathrm{L}^{-1}$ ): chemical oxygen demand (COD); total fraction $498 \pm 190$ (out of which $58 \%$ belongs to soluble fraction), $\mathrm{N}-\mathrm{NH}_{4}{ }^{+}$ of $34.1 \pm 16.3, \mathrm{~N}_{-} \mathrm{NO}_{2}{ }^{-}$of $0.9 \pm 0.8, \mathrm{~N}-\mathrm{NO}_{3}{ }^{-}$of $1.2 \pm 1.1$ and $\mathrm{P}_{-} \mathrm{PO}_{4}{ }^{3-}$ of $4.9 \pm 3.6$ and total suspended solids (TSS) and volatile suspended solids (VSS) of $0.17 \pm 0.06$ and $0.15 \pm 0.04 \mathrm{~g} \mathrm{~L}^{-1}$, respectively. Scenedesmus sp. biomass was harvested with an industrial centrifuge (OTC302-137, 10,000 rpm, WESTFALIA).

On the other hand, C. sorokiniana was grown in synthetic media (previously described) in $1 \mathrm{~L}$ flasks for biochemical methane potential assay. Previously to the AD, this biomass was concentrated with the centrifuge MegaFUGE 16R (Thermo Scientific, EEUU) at 5000 rpm during $15 \mathrm{~min}$. Second, C. sorokiniana biomass was frozen to compare the biogas production using a more easily degradable biomass than Scenedesmus sp. [15]. 


\section{Anaerobic digestion Inocula: anaerobic sludge}

The sludge samples (Table 1) were classified as mesophilic $\left(35^{\circ} \mathrm{C}\right)$ non-adapted to microalgae digestion and sludge samples adapted to microalgae digestion. Nonadapted anaerobic sludge samples were collected at the wastewater treatment plant of Valladolid (Valladolid, Spain, S1), Chiclana de La Frontera (Cádiz, Spain, S2), and La Reguera (Móstoles, Spain, S3). On the other hand, sludge samples adapted to microalgae digestion were collected in Chiclana de la Frontera (Cadiz, Spain). Those sludge samples were adapted to work at different operational temperatures, namely psychrophilic sludge $\left(15-25^{\circ} \mathrm{C}, \mathrm{S} 5\right)$, mesophilic $\left(35^{\circ} \mathrm{C}, \mathrm{S} 4\right)$ and thermophilic $\left(50{ }^{\circ} \mathrm{C}\right.$, S6). Therefore, from now on, since the objective of this investigation is the AD of microalgae biomass, S4, S5 and S6 will be considered "adapted sludge".

\section{Substrates: model compounds and microalgae biomass}

Bovine serum albumin (BSA) as protein substrate and cellulose as carbohydrate substrate were chosen as model compounds for assessing the specific methanogenic activity (SMA, g COD consumed/g VSS day) of the different anaerobic inocula. These substrates (proteins and carbohydrates) were selected based on their prevalence in microalgae biomass grown in wastewater [16]. These SMAs were used as an indicator of proteolytic and cellulolytic activity of anaerobic sludge samples. Second, all inocula were employed to digest Scenedesmus sp. (fresh biomass and poorly biodegradable) and C. sorokiniana (previously frozen and thus, easily biodegradable biomass). The fresh Scenedesmus sp. biomass was stored at $5{ }^{\circ} \mathrm{C}$ during less than 5 days to preserve its physiological characteristics.

\section{Biochemical methane potential (BMP)}

The anaerobic digestion was carried out in enclosed reactors in batch mode during approximately 20-30 reaction days. BMPs were considered finished when cumulative methane production was stable. Digestion bottles had a total volume of $0.12 \mathrm{~L}$ and were incubated at different temperatures depending on the inoculum. Temperatures were set at room temperature $\left(22-24{ }^{\circ} \mathrm{C}\right)$ for the psychrophilic assay (S5), at $35{ }^{\circ} \mathrm{C}$ for the mesophilic range (S1-S4) and at $50{ }^{\circ} \mathrm{C}$ for the thermophilic digestion (S6). Agitation was provided with an orbital shaker at $150 \mathrm{rpm}$. To ensure anaerobic conditions, bottles were purged with helium, closed with butyl rubber and aluminum caps. Calculations were set to achieve a final working volume of $0.07 \mathrm{~L}$, allowing a head space of $42 \%$ for biogas production. The inocula and anaerobic sludge samples were mixed with the different model substrates and algae biomass in a ratio of $\mathrm{COD}_{\text {substrate }} / \mathrm{VS}_{\text {inoculum }}$ of $0.5\left(\mathrm{~g} \mathrm{~g}^{-1}\right)$. Biodegradability assays were carried out in triplicates. The methane volume generated was calculated with the pressures determined in the head space bottle. The net methane production at standard temperature and pressure (STP) was calculated by subtracting the blank methane production to the amount of methane measured in each sample. To determine the endogenous methane production, bottles containing only anaerobic sludge samples were run as a blank.

\section{Analytical methods}

Total solids (TS), volatile solids (VS), total suspended solids (TSS), volatile suspended solids (VSS) and the total Kjeldahl nitrogen (TKN) were measured according to standard methods [17]. Total proteins were calculated by multiplying TKN values by 5.95 . Carbohydrates content were measured employing phenol sulphuric [18]. Colorimetric commercial methods were used for quantification of COD and ammonium (Merck, ISO 15705 y ISO 7150-1, respectively). $\mathrm{N}-\mathrm{NO}_{2}{ }^{-}, \mathrm{N}-\mathrm{NO}_{3}{ }^{-}$, and $\mathrm{P}-\mathrm{PO}_{4}{ }^{3-}$ were determined by ion chromatography (IC 9030, METHROM, Switzerland). Soluble fractions were obtained by centrifuging at $5000 \mathrm{rpm}$ for $15 \mathrm{~min}$ with the centrifuge MegaFUGE 16R (Thermo Scientific, USA) and later filtering by nylon filter of $0.45 \mu \mathrm{m}$ porous diameter. Biogas composition was determined by gas chromatography (Agilent 7820A) equipped with a $30 \mathrm{~m}$ column

Table 1 Characteristics and chemical properties of sludge samples (S1-S6) employed as inoculum for anaerobic digestion

\begin{tabular}{|c|c|c|c|c|c|c|}
\hline Parameter & S1 & S2 & S3 & S4 & S5 & S6 \\
\hline Location & Valladolid & Chiclana & La Reguera & Chiclana & Chiclana & Chiclana \\
\hline Substrate adaptation & Activated sludge & Activated sludge & Activated sludge & Microalgae & Microalgae & Microalgae \\
\hline Temperature adaptation & Meso- & Meso- & Meso- & Meso- & Psyc- & Therm- \\
\hline VS/TS & 0.64 & 0.64 & 0.58 & 0.71 & 0.77 & 0.69 \\
\hline VSS/TSS & 0.78 & 0.82 & 0.76 & 0.76 & 0.79 & 0.87 \\
\hline VSS/TS & 0.56 & 0.62 & 0.58 & 0.47 & 0.51 & 0.60 \\
\hline
\end{tabular}


(HP-PLOTQ, $0.53 \mathrm{~mm}, 40 \mu \mathrm{m}$ ) connected to a thermal conductivity detector at $250{ }^{\circ} \mathrm{C}$ and helium flow of $4.5 \mathrm{~mL} \mathrm{~min}^{-1}$ as gas carrier.

\section{Inocula microbial community analysis: pyrosequencing} Total DNA extraction of anaerobic sludge samples was performed using FastDNA Spin kit for soil (MPBiomedicals, LLC). Before DNA amplification reaction, samples were purified using commercial kit QiAmp DNA Microkit (QIAGEN, USA). Library preparation was made using set primer based on the capturing of 16s rRNA region as described in Klindworth et al. [19]. Sequencing samples were loaded in the MiSeq Platform from Illumina using a 300PE combination. Sequences were compared against the built rRNA database using a BLAST local alignment approach to associate each cluster to one taxonomical group from the database. Pyrosequencing was performed by Lifesequencing S.L. (University of Valencia, Spain).

\section{Statistical analysis}

Data were presented as means values \pm standard deviation of the mean and statistical significances were assessed by analysis of variance (ANOVA). Values were considered statistically significant when $p$ value was lower than 0.05 .

\section{Results and discussion}

Sludge samples and microalgae chemical characteristics All anaerobic sludge samples exhibited a standard VS/ TS ratio ranging $0.66 \pm 0.05$, VSS/TSS $=0.80 \pm 0.04$ and $\mathrm{VSS} / \mathrm{VS}=0.57 \pm 0.07$. These values were in good agreement with other sludge samples used for BMP tests [20, 21]. In this manner, despite the different feedstock used during their previous activity, namely sewage sludge (mixture of primary and secondary sludge) (S1, S2 and S3) or microalgae biomass (S4, S5 and S6), all of them were within the usual values.

With regard to the microalgae biomass employed as substrate, both biomass showed a prevalent protein composition (Table 2). This feature is quite normal of microalgae grown without any stressful condition [20]. In the case of Scenedesmus sp., proteins were followed by carbohydrates (approx. 34\%) and a minor proportion of lipids (11\%). Opposite to that, C. sorokiniana displayed a higher lipid content (24\%) than the carbohydrate fraction (10\%). It should be noted that this strain has been reported to have a particular tendency to accumulate lipids [22, 23].

\section{Sludge samples: anaerobic microbiome}

Pyrosequencing was performed to characterize the anaerobic microbiome of all sludge samples. With regard to Shannon's index of diversity at genera level, all the sludge samples were in the range of 1.36-1.75, exception
Table 2 Macromolecular distribution of the microalgae biomass employed as feedstock for anaerobic digestion

\begin{tabular}{lll}
\hline Chemical parameter & Scenedesmus sp. & C. sorokiniana \\
\hline TS g L $^{-1}$ & $26.7 \pm 0.7$ & $37.5 \pm 0.2$ \\
VS g L $^{-1}$ & $23.0 \pm 1.2$ & $34.1 \pm 0.0$ \\
Carbohydrates (\%) & $33.8 \pm 2.4$ & $10.4 \pm 0.7$ \\
Proteins (\%) & $41.0 \pm 0.7$ & $56.3 \pm 0.7$ \\
Lipids (\%) & $11.5 \pm 3.4$ & $24.1 \pm 0.7$ \\
Ash (\%) & $13.8 \pm 2.5$ & $9.2 \pm 0.3$ \\
\hline
\end{tabular}

made for S1 and S6, which exhibited 3.07 and 0.32, respectively. This indicated that the diversity of S1 was considerably higher than the rest of sludge samples while S6 displayed a highly specific consortium in which the biodiversity was really reduced.

At phylum level, bacterial distribution was mainly represented by Proteobacteria. This phylum ranged $46-51 \%$ of the bacteria retrieved in the adapted sludge samples while in S2, the prevalence of Proteobacteria was outcompeted by Actinobacteria (27\%) and S1 and S3 exhibited 35 and $42 \%$ of the bacterial population (Fig. 1a). Proteobacteria are frequently reported to be present at high proportion in anaerobic sludge [24]. Groups of Proteobacteria as Rhizobiales, Rhodobacterales, Sphingomonadales and Burkholderiaels-Comamonadaceae found in this work have been also reported in studies related to microalgae-based wastewater treatment [25]. Reactors S3-6 were adapted to digest microalgae-bacteria consortia harvested from a photosynthetic-based wastewater treatment. This inocula adaptation can explain the prevalent presence of this group of bacteria in these inocula. It has been shown that Proteobacteria population increases from 13 to $50 \%$ when changing the feeding from sewage sludge to raw Chlorella [26]. This fact was also observed in the present investigation, in which the sludge samples adapted to digest microalgae (S4-S6) exhibited slightly higher population of this phylum. This feature could be explained by the above-mentioned prevalence of proteins in microalgae biomass.

The second main phyla retrieved from the sludge samples was Firmicutes. Non-adapted sludge (S1-S3) showed a relative abundance of approximately 20\% of Firmicutes (Fig. 1a). This bacterial community is also normally present in anaerobic sludge digesting sewage sludge. Interestingly, adapted sludge samples (S4-S6) decreased their abundance of Firmicutes in psychrophilic and mesophilic sludge to around 10\% while that of the thermophilic displayed $28 \%$ relative abundance. The sequences were mainly affiliated to the order Clostridiales. More specifically, the relative abundance of Clostridia in S2-S5 were in the narrow range of $62-66 \%$ of the Firmicutes, while S1 and 


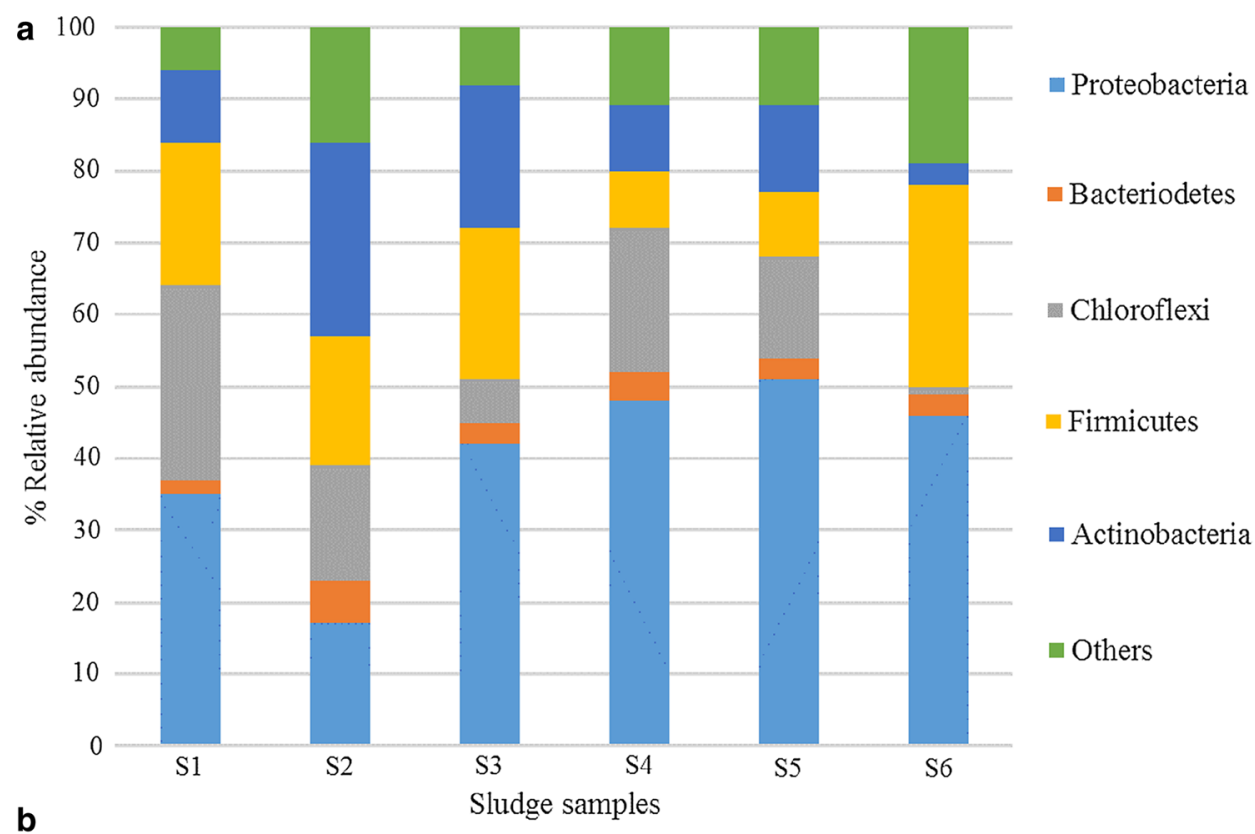

b

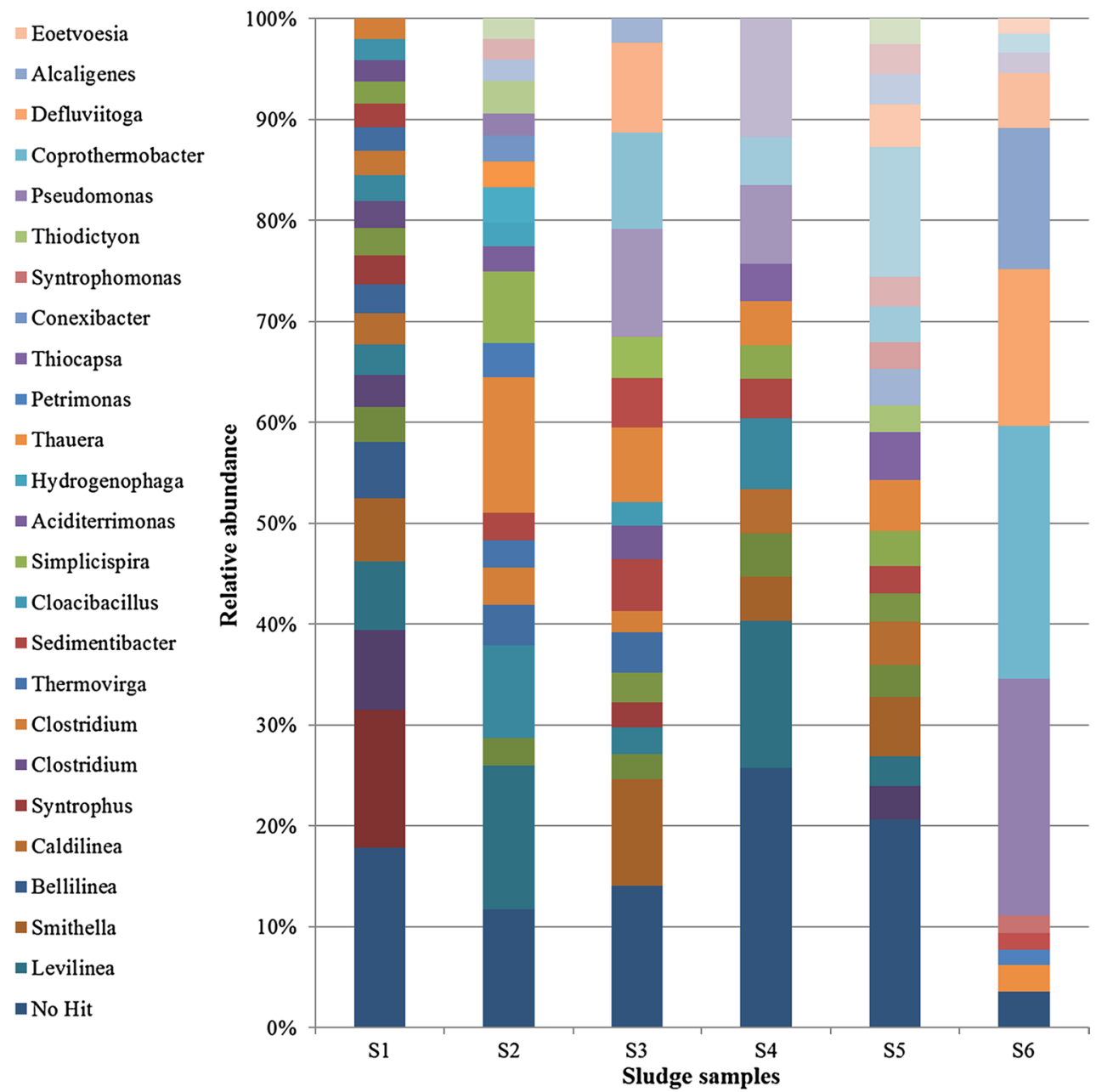

Fig. 1 Taxonomic profiles at phylum (a) and genera (b) level for the bacterial community of the different inoculum sources used in the BMPs 
S6 showed markedly higher percentages (86 and 96\%, Fig. 1b). It is important to note that Clostridia are responsible of conducting macromolecules hydrolysis [27] and syntrophic acetate oxidation coupled with hydrogenotrophic methanogenesis [28]. Clostridiales is an order of obligate anaerobic bacteria with chemoorganotrophic fermentative metabolisms. Members of this group of microorganisms are frequent in soils, sediments, rumen and intestinal tracts of animals and insects. In addition, Clostridiaceae family members have in common their saccharolytic fermentative metabolism in environmental substrate decomposition [29].

Bacteroidetes were present at really low relative abundance (2-6\% for all sludge samples). Bacteroidetes are anaerobic microorganisms which are included in animal intestinal microflora [30] due to its importance in cellulose and protein degradation [31]. When digesting raw and thermally pretreated Chlorella, Bacteroidetes abundancy increased to $20 \%$ with regard to $12 \%$ registered in the inoculum used as seed of the reactor (adapted to digest sewage sludge, [26]). Likewise, Bacteroidetes also found the dominant phylum in the digestion of Scenedesmus obliquus at mesophilic range [32]. Nevertheless, in the present study, their abundance remained low regardless of the inoculum source.

Chloroflexi phylum are aerobic bacteria commonly found in activated sludge systems [33], and therefore, this phylum usually ends up in the anaerobic digesters of wastewater treatment plants. Due to their filamentous morphology, their presence is normally associated to bulking phenomena. In this manner, no trend could be withdrawn in sludge samples collected from wastewater treatment and their relative abundance varied from $6 \%$ for $\mathrm{S} 3$ to $27 \%$ for S1. A striking feature was the fact that the thermophilic adapted sludge showed 1\% of this phylum (Fig. 1a). This value was really low when compared to the rest of sludge samples. Nevertheless, this feature was in agreement with Greses et al. [34] who also reported extremely low relative abundance (1.1\%) in a thermophilic CSTR fed with Scenedesmus. Authors attributed this fact to the low-ammonium tolerance of this phyla and the operational temperature. It should be also highlighted that S6 displayed 16\% Thermotogae relative abundance (classified as other in Fig. 1a). The presence of this phylum was negligible in the rest of the sludge samples. Thermotogae have been described to release hydrolytic enzymes catalyzing the degradation of polysaccharides into acetate, carbon dioxide and hydrogen [35] and also to play a key role in interspecies hydrogen transfer [36]. Thermotogae species are obligate anaerobes and hyperthermophiles bacteria found in large range extremophile environments, including mammalian, ruminant and termite digestive tracts. All those ecophysiology characteristics explain this abundance in S6 sludge [37].

The archaeal domain accounted for $7-8 \%$ of the identified population in the case of sludge adapted to digest sewage sludge (S1-S3), while this value decreased to $3-4 \%$ for all the sludge samples adapted to digest microalgae (S4-S6). In this manner, it was clear that microalgae digestion affected archaeal relative abundance. With regard to the phyla determined in the different sludge samples, the abundance of the strict acetotrophic Methanosaeta was prevailing in S1-S5, ranging from 67 to $82 \%$ of the archaeal population (Fig. 2). Opposite to that, methanogenesis in the thermophilic sludge S6 was mainly conducted by Methanothermobacter and Methanosarcina (59 and 40\% of the archaeal population retrieved in the sample, respectively). Methanothermobacter is a hydrogenotrophic methanogen [38] while Methanosarcina is more versatile and can metabolize both hydrogen and acetate as energy source [39]. Indeed, acetoclastic methanogens are commonly outcompeted by hydrogenotrophic methanogens in thermophilic digesters [40]. This fact is related to the lower stability of thermophilic digestion conditions as a result of acetate accumulation and acidification. In this manner, according to the bacterial and archaeal population it can be assumed that this was the case as well in S6. Hydrogenotrophic methanogens were also represented by the Methanomicrobiales community identified in $\mathrm{S} 1-\mathrm{S} 5$, however, their relative abundance was much lower than in the thermophilic digester (10-30\% vs. 60\%).

There are no other studies published that focused in the comparison of the microbial population inocula adapted to digest microalgae and sewage sludge at different temperatures ranges. As an example, many other articles have characterized the microbial composition of inocula adapted to digest microalgae and activated sludge

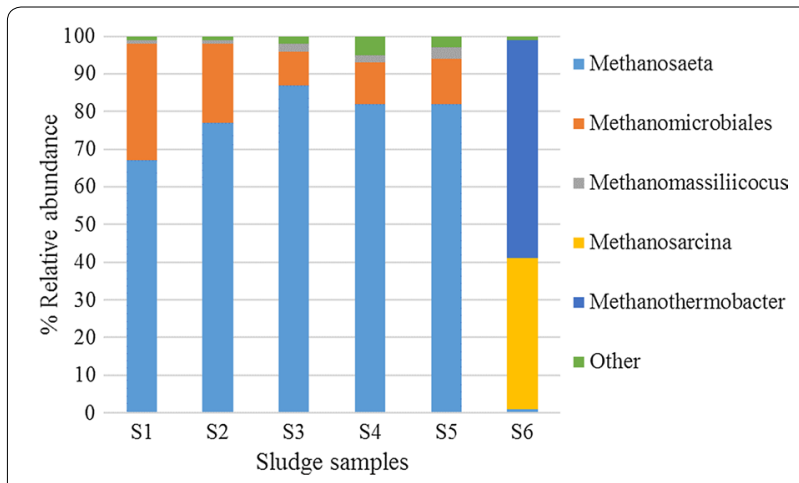

Fig. 2 Taxonomic profiles at phylum level for the archaeal community of the different inoculum sources used in the BMPs 
only at one temperature range $[24,25,29,34]$. The novelty of this article is the comparison of different microbiome composition adapted to three different operational temperature ranges and feedstocks (microalgae and raw sewage). Overall, the anaerobic microbiome analysis of all sludge samples used in the present study evidenced different bacterial and archaeal population not only in terms of relative abundances but also in the phyla and genera identified. In this manner, it could be concluded that the different feedstocks fed in the digesters (sewage sludge and microalgae biomass) as well as the operational temperature had an impact on the inoculum sources.

\section{Specific methanogenic activity of sludge samples toward model substrates: BSA and cellulose}

According to Angelidaki et al. [41] specific methanogenic activity (SMA) was measured using different model substrates representing proteins (BSA) and carbohydrates (cellulose). Those two substrates were selected as model for protein and carbohydrate degradation since those are the fractions which present lower biodegradability in the microalgae biomass $[16,20]$. As it can be seen in Fig. 3, SMA was higher and faster for the BSA model substrate than with cellulose. The sludge S1 exhibited considerably higher SMA than the adapted sludge samples. More specifically, in the first day of digestion, S1 displayed threefold SMA (0.157 g COD consumed/g VS day) than S4, S5 and S6 (0.055 g COD consumed/g VS day, Fig. 3a). This fact was probably mediated by the higher microbial
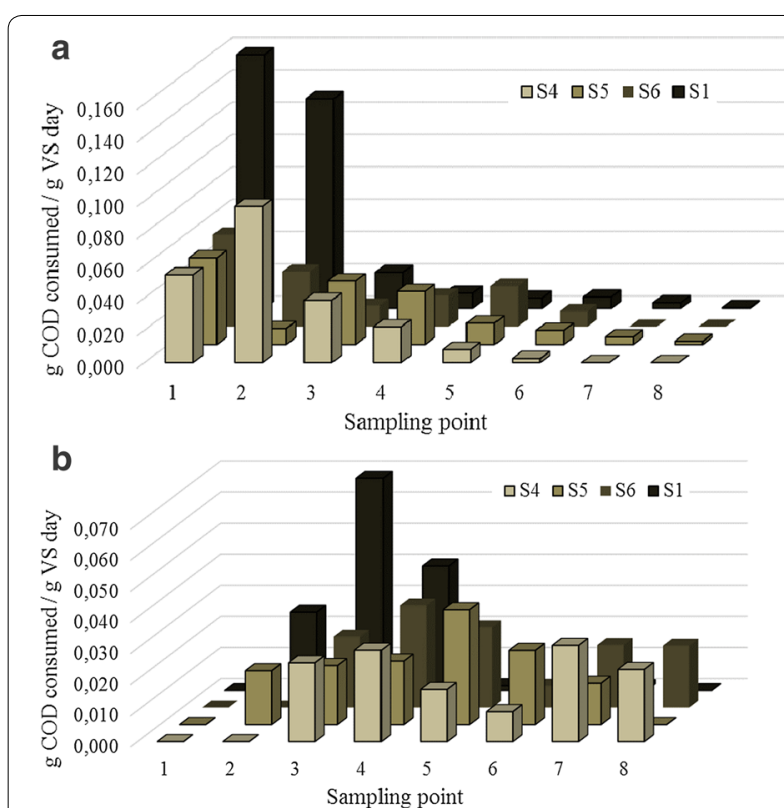

Fig. 3 Specific methanogenic activities (SMA) towards model substrates: $\mathbf{a} \mathrm{BSA}$ and $\mathbf{b}$ cellulose diversity encountered in this sludge in comparison to the adapted ones (Section "Sludge samples: anaerobic microbiome"). A higher diversity implies more options that the appropriate degrading microorganisms is within the microbial consortium, which ultimately implies more degrading pathways that are strictly required for anaerobic digestion. Even though digesters with low diversity might operate under stable conditions, higher microbial diversity ensures a higher resistance resilience and functional redundancy, which ultimately results in good $\mathrm{AD}$ performances [42].

Since hydrolysis is the first step on anaerobic digestion, it can be assumed that these data reflected a higher proteolytic activity of S1 with regard to the other tested sludge samples. Proteolytic bacteria occur in high numbers in anaerobic digesters receiving raw sewage sludge [24]. This would support the fact that S1-SMA was the highest since the other sludge samples were adapted to digest mainly microalgae biomass. More interestingly, S1 was the sludge with lower Proteobacteria relative abundance (35\% out of the total bacterial number vs. $46-51 \%$ for the adapted sludge, Fig. 1a). In this manner, it can be highlighted that despite the lower relative abundance, the enzymes secreted by the proteolytic bacteria of S1 were more suitable and/or active for BSA hydrolysis. The SMA using BSA as a substrate was diminished along digestion time. After approximately 7 days of digestion, the SMA attained for BSA was minimal (Fig. 3a) while the one corresponding to cellulose as model substrate slowly increased (Fig. 3b). Thus, it could be concluded that all sludge samples had a higher proteolytic activity than cellulolytic toward the model substrates. One or other prevalent hydrolytic activity strongly depend on the selected inoculum. In principle, protein hydrolysis is slower than the hydrolysis of carbohydrates [43]. Nevertheless, hydrolysis constants and, therefore, methane production is highly dependent on several factors such as microbial community, selected model substrate and digestion temperature. In this manner, a wide range of hydrolytic constant might be found in the literature [44].

As observed for S1 and the adapted sludge samples (S4-S6), the SMA obtained when using cellulose model substrate was also clearly different (Fig. 3b). The only common behavior for all the sludge samples was the lack of methane production during the 2-3 first days of digestion. Similarly to what it was observed in the previous case, S1 exhibited three-fold higher SMA than the adapted sludge samples after 5 days of digestion $(0.07 \mathrm{~g}$ COD consumed/g VS day for S1 vs $\pm 0.022 \mathrm{~g}$ COD consumed/g VS day for S4-S6). Once again, the higher biodiversity determined in S1 mediated higher SMA for cellulose than the rest of the sludge samples. While in the case of the proteolytic activity, SMA steadily decreased 
along digestion, in the case of cellulolytic activity, the sludge samples responded differently. Almost barely any activity was observed after 7 days of digestion for S1, while the adapted sludge samples maintained an SMA of 0.021-0.024 along 19 days of digestion regardless of the digestion temperature. This fact resulted in a similar methane yield but lower methane productivity of the adapted sludge samples.

\section{Microalgae digestion using different anaerobic sludge inocula}

Based on the above-mentioned analysis, it was obvious that differences existed among the inocula used herein. Incubation with different inocula at mesophilic range resulted in similar BMP values for Scenedesmus sp. biomass, since no significant differences were observed between the different non-adapted mesophilic inocula (Fig. 4a). S1-S3 supported methane yields of $63.1 \pm 3.1 \mathrm{~mL} \mathrm{CH}_{4}$ g COD in ${ }^{-1}$. Slightly higher values $\left(79.2 \pm 3.1 \mathrm{~mL} \mathrm{CH}_{4} \mathrm{~g} \mathrm{COD} \mathrm{in}^{-1}\right)$ were determined for the sludge adapted to digest microalgae biomass (S4). With regard to the sludge samples adapted to digest
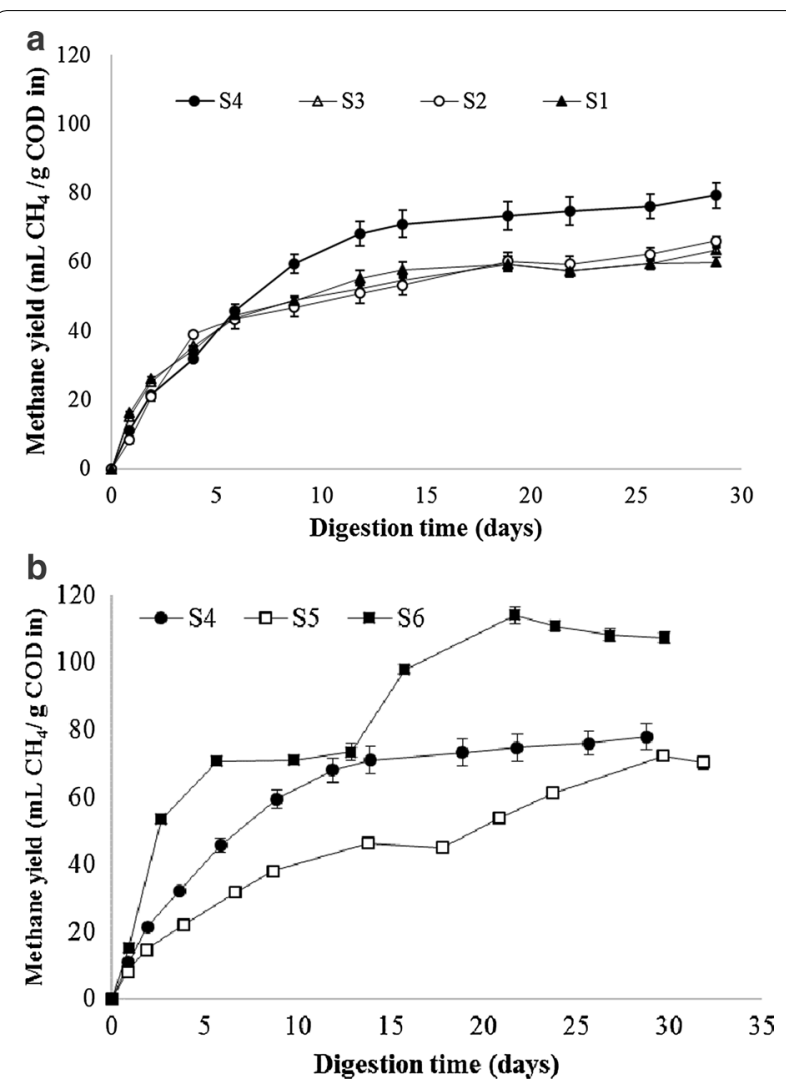

Fig. 4 Cumulative methane production achieved by mesophilic sludge samples (a) and adapted to microalgae sludge samples (b) when digesting Scenedesmus sp. biomass microalgae biomass at different temperature, methane yields increased concomitantly with digestion temperature. More specifically, the values attained were $63.4 \pm 1.5,79.2 \pm 3.1$ and $108.2 \pm 1.9 \mathrm{~mL} \mathrm{CH}_{4} \mathrm{~g} \mathrm{COD} \mathrm{in}^{-1}$ for psychrophilic, mesophilic and thermophilic digestions, respectively (Fig. 4b). Despite of the differences registered in terms of the anaerobic microbiome and the metabolic activities towards model substrates, no big differences were evidenced among the mesophilic sludge samples. This feature was opposite to what it is described in the literature when testing different inocula sources for the digestion of different biomass. For instance, Gu et al. [45] evaluated different inocula sources on the anaerobic degradation of rice straw and their results showed that digested manures were more active than anaerobic sludge. Similarly, Cordoba et al. [11] also proved that the selection of inocula sources could affect the anaerobic digestion of liquid swine wastewater. Nevertheless, in some cases, the effect of inocula source is only detectable depending on the targeted substrate [46]. In the present study, the only remarkable differences were observed for the sludge samples adapted to digest microalgae biomass at meso- and thermophilic range. In principle, thermophilic digesters are usually operated as close as possible to $50{ }^{\circ} \mathrm{C}$. This temperature, being close to the optimum for enzymatic activity, frequently results in faster reaction rates compared to mesophilic digestion, leading to shorter retention times. Therefore, advantages of thermophilic digestion involve faster hydrolysis and acidogenesis while being more sensitive to ammonia toxicity. Within thermophilic digestion of microalgae in BMP mode, Capson-Tojo et al. [47] digested lipid-extracted Nannochloropsis gaditana at mesophilic and thermophilic range. They concluded that mesophilic digestion supported higher anaerobic biodegradability than thermophilic, however, they also observed that this later digestion temperature supported higher COD solubilization. This was attributed to the fact that the used anaerobic sludge was indeed mesophilic for both assays, and thus, the digestion run at thermophilic range was too short to get the anaerobic microorganisms adapted to the thermophilic temperature. As a matter of fact, the investigation presented herein proved that when the inoculum was adapted to digest microalgae at thermophilic conditions, methane yield was the highest of all trials. Overall, adapted sludge samples to the digestion of microalgae have shown to be beneficial for the biodegradation of Scenedesmus sp. Digestion conducted at psychrophilic range supported similar methane yields than the sludge samples adapted to digest sewage sludge (Fig. 4). Therefore, the same yield could be achieved at lower energy cost for maintaining the digester temperature. Methane yields of psycro- and mesophilic digestions were quiet similar most likely due 
to their anaerobic microbiome resemblance (bacterial and archaeal population). The most remarkable difference in methane yields was achieved by the thermophilic consortium, which provided the highest value. Methane yield at thermophilic range was 1.36-fold higher than mesophilic range. The benefits of using thermophilic digestion over mesophilic digestion seems to be specie specific [5]. According to Zamalloa et al. [48], the digestion of S. obliquus in thermophilic range increased the methane yield by $24 \%$ when compared to the digestion in mesophilic range operating continuous digesters. To the best of the authors' knowledge, no thermophilic digestion in batch mode has been published for Scenedesmus and thus, no comparison could be made. Nevertheless, pretreatments devoted to enhance methane yields of this microalgae strain in BMPs reported similar enhancement values [49]. Thus, this study highlighted the potential of working with highly specific consortia to increase methane yield. Given the differences in the anaerobic microbiomes of the different sludge samples, it can be concluded that the microorganism's consortium developed in the adapted sludge was linked to the higher methane yields achieved. As hypothesized by Greses et al. [34] the results obtained herein seemed to confirm that the high relative abundance of Firmicutes in the thermophilic sludge (Fig. 2a) compared to the rest of the sludge samples could be the explanation for the higher methane yields achieved with this inocula.

According to De Vrieze et al. [46] the substrate employed could be of paramount importance when dealing with the effect of different inocula sources. Since Scenedesmus sp. is most probably the hardest microalgae to digest [15], a similar approach was conducted with some easier digestible microalgae. The results attained for the digestion of Chlorella sorokiniana upon the use of selected inocula was shown in Fig. 5. The main difference was the methane productivity while the final yields were not affected by the inoculum. After 15 days of digestion, methane yields ranged $105-114 \mathrm{~mL} \mathrm{CH}_{4} \mathrm{~g}^{\mathrm{COD}}$ in $^{-1}$ for the three tested sludge. In this context, the beneficial effect observed on the anaerobic digestion of Scenedesmus sp. by the inoculum adapted to digest microalgae (S4) was not evident in the digestion of $C$. sorokiniana. Nevertheless, it cannot be neglected that the productivity was higher for S4 than for the rest of the sludge samples. In this manner, S4 achieved maximum methane yield after 10 days of digestion while S1 required 18 days, despite of the highest specific methanogenic activity registered for this sludge (Fig. 3). When compared to C. sorokiniana, the better results obtained for Scenedesmus sp. were related to the fact that the microalgae biomass digested by S4-S5 and S6 was mainly composed by Scenedesmus, Dictyosphaerium, Coelastrum,

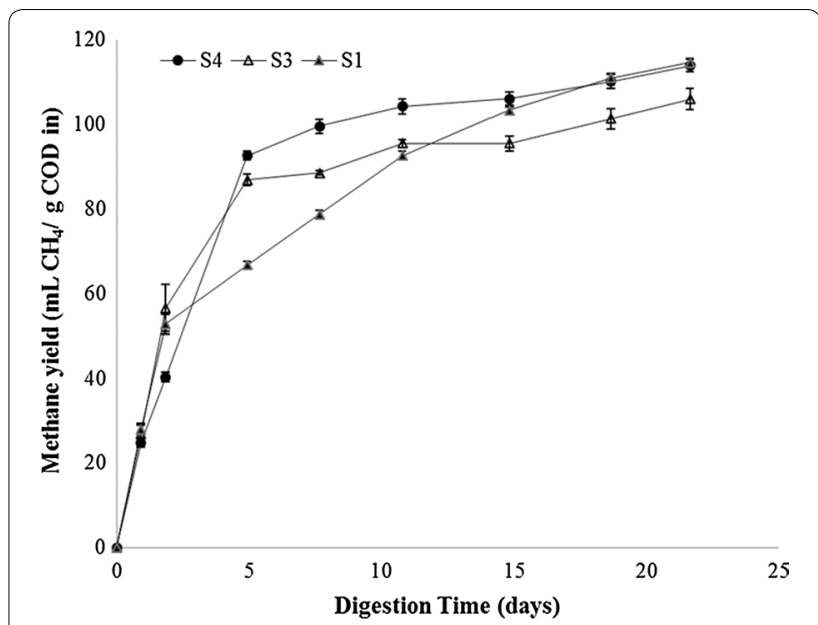

Fig. 5 Cumulative methane production achieved by mesophilic sludge samples when digesting Chlorella sorokiniana biomass

Micractinium and Chlorella. Most probably, the anaerobic microbiome developed in the anaerobic inocula of the adapted sludge samples was particularly suitable for the digestion of Scenedesmus and thus, the positive effect was more evident in that biomass.

\section{Conclusion}

This research demonstrated that despite the differences related to their anaerobic microbiome and SMA towards model substrates, the anaerobic digestion of microalgae biomass was not influenced by different inocula sources adapted to digest sewage sludge. Opposite to that, the sludge samples adapted to digest microalgae biomass exhibited better performances. Mesophilic sludge adapted to the digestion of microalgae consortium mainly composed by Scenedesmus showed greater methane yields than adapted to digest sewage sludge. The same could not be concluded with other microalgae biomass (Chlorella). Thus, it could be concluded that the anaerobic microbiome was tailored to degrade mainly Scenedesmus. With regard to the adapted inocula, psychrophilic digestion displayed lower methane productivity while methane yield was comparable to mesophilic digestion with adapted sludge. Most remarkably was the methane yield achieved by the thermophilic adapted sludge. Even though, a high microbial diversity might play a positive role in maintaining the stability of the system, the anaerobic microbiome of thermophilic digester presented a low diversity but highly efficient for the anaerobic digestion of Scenedesmus sp. The relative abundance of Firmicutes, particularly Clostridia, and Proteobacteria together with an important abundance of hydrogenotrophic methanogens was highlighted in this inoculum. Linking process engineering to microbial community in $\mathrm{AD}$ reactors 
could bring new insights to pay the way out to a better digester performance and avoid pretreatments by working with a highly specific anaerobic microbiome.

\section{Authors' contributions}

CGF designed, analyzed the data and wrote the manuscript. SBV performed the experiments. IG, MB, MF and AZ contributed to the writing and critical reviewing of the manuscript. All authors discussed the results and commented on the manuscript. All authors read and approved the final manuscript.

\section{Author details}

${ }^{1}$ Biotechnological Processes Unit, IMDEA Energy, Madrid, Spain. ${ }^{2}$ Aqualia Gestión Integral del Agua SA, Madrid, Spain. ${ }^{3}$ Biofuels Unit, CIEMAT, Madrid, Spain.

\section{Acknowledgements}

Not applicable.

\section{Competing interests}

The authors declare that they have no competing interests.

\section{Consent for publication}

The authors agree to publish in the journal.

\section{Funding}

The authors wish to thank the Spanish Ministry of Economy and Competitiveness for the financial support provided through the grants ENE2013-45416-R and RYC-2014-16823. We would also like to acknowledge the Community of Madrid for the support offered in the framework of the project INSPIRA-1 (S2013/ABI-2783) and in addition to the WWTP of Valladolid (Spain) for kindly supplying the anaerobic sludge sample.

\section{Publisher's Note}

Springer Nature remains neutral with regard to jurisdictional claims in published maps and institutional affiliations.

Received: 17 April 2018 Accepted: 25 June 2018

Published online: 29 June 2018

\section{References}

1. Pflüger S. European biogas industry now and beyond 2020. European Biogas Association; 2017. http://european-biogas.eu/wp-content/uploa ds/2017/02/5-Susanna_European-biogas-industry-now-and-beyon d-2020.pdf. Accessed 1 Mar 2018.

2. Shilton A, Guieysse B. Sustainable sunlight to biogas is via marginal organics. Curr Opin Biotechnol. 2010;21:287-91.

3. Ometto F, Quiroga G, Psenicka P, Whitton R, Jefferson B, Villa R. Impacts of microalgae pre-treatments for improved anaerobic digestion: thermal treatment, thermal hydrolysis, ultrasound and enzymatic hydrolysis. Water Res. 2014;65:350-61.

4. Angelidaki I, Sanders W. Assessment of the anaerobic biodegradability of macropollutants. Rev Environ Sci Biotechnol. 2004;3:117-29.

5. Gonzalez-Fernandez C, Sialve B, Molinuevo-Salces B. Anaerobic digestion of microalgal biomass: challenges, opportunities and research needs. Bioresour Technol. 2015;2004(198):896-906.

6. Passos F, Uggetti E, Carrere H, Ferrer I. Pretreatment of microalgae to improve biogas production: a review. Bioresour Technol. 2014:172:403-12.

7. Mendez L, Mahdy A, Demuez M, Ballesteros M, González-Fernández C. Effect of high pressure thermal pretreatment on Chlorella vulgaris biomass: organic matter solubilisation and biochemical methane potential. Fuel. 2014;117(Part A):674-9.

8. Passos F, Sole M, Garcia J, Ferrer I. Biogas production from microalgae grown in wastewater: effect of microwave pretreatment. Appl Energy. 2013:108:168-75
9. Xu FQ, Shi J, Lv W, Yu ZT, Li YB. Comparison of different liquid anaerobic digestion effluents as inocula and nitrogen sources for solid-state batch anaerobic digestion of corn stover. Waste Manag. 2013;33:26-32.

10. Sutherland AD, Varela JC. Comparison of various microbial inocula for the efficient anaerobic digestion of Laminaria hyperborea. BMC Biotechnol. 2014;14:7.

11. Cordoba V, Fernandez M, Santalla E. The effect of different inoculums on anaerobic digestion of swine wastewater. J Environ Chem Eng. 2016:4:115-22.

12. De Francisci D, Kougias PG, Treu L, Campanaro S, Angelidaki I. Microbial diversity and dynamicity of biogas reactors due to radical changes of feedstock composition. Bioresour Technol. 2015;176:56-64.

13. Becker JG, Berardesco G, Rittmann BE, Stahl DA. Effects of endogenous substrates on adaptation of anaerobic microbial communities to 3-chlorobenzoate. Appl Environ Microbiol. 2006;72:449-56.

14. Lowe SE, Jain MK, Zeikus JG. Biology, ecology, and biotechnological applications of anaerobic bacteria adapted to environmental stresses in temperature, pH, salinity, or substrates. Microbiol Rev. 1993;57:451-509.

15. Gonzalez-Fernandez C, Sialve B, Bernet N, Steyer JP. Impact of microalgae characteristics on their conversion to biofuel. Part II: focus on biomethane production. Biofuel Bioprod Biorg. 2012;6:205-18.

16. Molinuevo-Salces B, Mahdy A, Ballesteros M, González-Fernández C. From piggery wastewater nutrients to biogas: microalgae biomass revalorization through anaerobic digestion. Renew Energy. 2016;96(Part B):1103-10.

17. Federation WE, American Public Health A. Standard methods for the examination of water and wastewater. Washington, DC: American Public Health Association (APHA); 2005.

18. DuBois M, Gilles KA, Hamilton JK, Rebers PA, Smith F. Colorimetric method for determination of sugars and related substances. Anal Chem. 1956:28:350-6.

19. Klindworth A, Pruesse E, Schweer T, Peplies J, Quast C, Horn M, Gloeckner FO. Evaluation of general $16 \mathrm{~S}$ ribosomal RNA gene $\mathrm{PCR}$ primers for classical and next-generation sequencing-based diversity studies. Nucleic Acids Res. 2013;41:e1.

20. Mendez L, Mahdy A, Ballesteros M, Gonzalez-Fernandez C. Methane production of thermally pretreated Chlorella vulgaris and Scenedesmus sp. biomass at increasing biomass loads. Appl Energy. 2014;129:238-42.

21. Mahdy A, Mendez L, Blanco S, Ballesteros M, González-Fernández C. Protease cell wall degradation of Chlorella vulgaris: effect on methane production. Bioresour Technol. 2014;171:421-7.

22. Li TT, Gargouri M, Feng J, Park JJ, Gao DF, Miao C, Dong T, Gang DR, Chen SL. Regulation of starch and lipid accumulation in a microalga Chlorella sorokiniana. Bioresour Technol. 2015;180:250-7.

23. Juntila DJ, Bautista MA, Monotilla W. Biomass and lipid production of a local isolate Chlorella sorokiniana under mixotrophic growth conditions. Bioresour Technol. 2015;191:395-8.

24. Siebert ML, Toerien DF. The proteolytic bacteria present in the anaerobic digestion of raw sewage sludge. Water Res. 1969;3:241-50.

25. Fulbright SP, Robbins-Pianka A, Berg-Lyons D, Knight R, Reardon KF, Chisholm ST. Bacterial community changes in an industrial algae production system. Algal Res. 2018;31:147-56.

26. Sanz JL, Rojas P, Morato A, Mendez L, Ballesteros M, González-Fernández C. Microbial communities of biomethanization digesters fed with raw and heat pre-treated microalgae biomasses. Chemosphere. 2017;168:1013-21.

27. Tracy BP, Jones SW, Fast AG, Indurthi DC, Papoutsakis ET. Clostridia: the importance of their exceptional substrate and metabolite diversity for biofuel and biorefinery applications. Curr Opin Biotechnol. 2012:23:364-81.

28. Mosbaek F, Kjeldal H, Mulat DG, Albertsen M, Ward AJ, Feilberg A, Nielsen $J$ L. Identification of syntrophic acetate-oxidizing bacteria in anaerobic digesters by combined protein-based stable isotope probing and metagenomics. ISME J. 2016;10:2405-18.

29. Dworkin M. The prokaryotes. In: Dworkin M, Falkow S, Rosenberg E, Schleifer KH, Stackebrandt E, editors. Bacteria: Firmicutes, Cyanobacteria, vol. 4. Berlin: Springer Science \& Business Media; 2006.

30. Dworkin M. The prokaryotes. In: Dworkin M, Falkow S, Rosenberg E, Schleifer KH, Stackebrandt E, editors. Proteobacteria: delta and epsilon subclasses. Deeply rooting bacteria, vol. 7. Berlin: Springer Science \& Business Media; 2006. 
31. Riviere D, Desvignes V, Pelletier E, Chaussonnerie S, Guermazi S, Weissenbach J, Li T, Camacho P, Sghir A. Towards the definition of a core of microorganisms involved in anaerobic digestion of sludge. ISME J. 2009;3:700-14.

32. Wirth R, Lakatos G, Bojti T, Maroti G, Bagi Z, Kis M, Kovacs A, Acs N, Rakhely $\mathrm{G}$, Kovacs KL. Metagenome changes in the mesophilic biogas-producing community during fermentation of the green alga Scenedesmus obliquus. J Biotechnol. 2015;215:52-61.

33. Kragelund $C$, Levantesi $C$, Borger $A$, Thelen $K$, Eikelboom D, Tandoi $V$, Kong YH, van der Waarde J, Krooneman J, Rossetti S, Thomsen TR, Nielsen PH. Identity, abundance and ecophysiology of filamentous Chloroflexi species present in activated sludge treatment plants. FEMS Microbiol Ecol. 2007;59:671-82

34. Greses S, Gaby JC, Aguado D, Ferrer J, Seco A, Horn SJ. Microbial community characterization during anaerobic digestion of Scenedesmus spp. under mesophilic and thermophilic conditions. Algal Res. 2017;27:121-30.

35. Huber R, Hannig M. Thermotogales, the prokaryotes. Berlin: Springer; 2006. p. 899-922.

36. Johnson MR, Conners SB, Montero Cl, Chou CJ, Shockley KR, Kelly RM. The Thermotoga maritima phenotype is impacted by syntrophic interaction with Methanococcus jannaschii in hyperthermophilic coculture. Appl Environ Microbiol. 2006;72:811-8.

37. Sowers KR, Watts JEM. 33 The study of strictly anaerobic microorganisms. In: Rainey FA, Oren A, editors. Methods in microbiology, vol. 35. New York: Elsevier; 2006. p. 757-82.

38. Maus I, Koeck DE, Cibis KG, Hahnke S, Kim YS, Langer T, Kreubel J, Erhard M, Bremges A, Off S, Stolze Y, Jaenicke S, Goesmann A, Sczyrba A, Scherer P, Konig H, Schwarz WH, Zverlov W, LiebI W, Puhler A, Schluter A, Klocke M. Unraveling the microbiome of a thermophilic biogas plant by metagenome and metatranscriptome analysis complemented by characterization of bacterial and archaeal isolates. Biotechnol Biofuels. 2016;9:171.
39. Boone DR, Whitman WB, Rouvière P. Diversity and taxonomy of methanogens. In: Ferry JG, editor. Methanogenesis. Berlin: Springer; 1993. p. 35-80.

40. Demirel B, Scherer P. The roles of acetotrophic and hydrogenotrophic methanogens during anaerobic conversion of biomass to methane: a review. Rev Environ Sci Biotechnol. 2008;7:173-90.

41. Angelidaki I, Alves M, Bolzonella D, Borzacconi L, Campos JL, Guwy AJ, Kalyuzhnyi S, Jenicek P, van Lier JB. Defining the biomethane potential (BMP) of solid organic wastes and energy crops: a proposed protocol for batch assays. Water Sci Technol. 2009;59:927-34.

42. Carballa M, Regueiro L, Lema JM. Microbial management of anaerobic digestion: exploiting the microbiome-functionality nexus. Curr Opin Biotechnol. 2015;33:103-11.

43. Pavlostathis SG, Giraldo-Gomez E. Kinetics of anaerobic treatment. Water Sci Technol. 1991;24:35-59.

44. Ahring BK, Angelidaki I, de Macario CC, Gavala HN, Hofman-Bang J, Elfering SO, Raskin L, Stams AJ, Westermann P, Zheng D. Biomethanation I, vol. 81. Berlin: Springer; 2003.

45. Gu Y, Chen X, Liu Z, Zhou X, Zhang Y. Effect of inoculum sources on the anaerobic digestion of rice straw. Bioresour Technol. 2014;158:149-55.

46. De Vrieze J, Raport L, Willems B, Verbrugge S, Volcke E, Meers E, Angenent LT, Boon N. Inoculum selection influences the biochemical methane potential of agro-industrial substrates. Microb Biotechnol. 2015;8:776-86.

47. Capson-Tojo G, Torres A, Munoz R, Bartacek J, Jeison D. Mesophilic and thermophilic anaerobic digestion of lipid-extracted microalgae $\mathrm{N}$. gaditana for methane production. Renew. Energy. 2017;105:539-46.

48. Zamalloa C, Boon N, Verstraete W. Anaerobic digestibility of Scenedesmus obliquus and Phaeodactylum tricornutum under mesophilic and thermophilic conditions. Appl Energy. 2012;92:733-8.

49. Gonzalez-Fernandez C, Sialve B, Bernet N, Steyer JP. Thermal pretreatment to improve methane production of Scenedesmus biomass. Biomass Bioenergy. 2012;40:105-11.
Ready to submit your research? Choose BMC and benefit from:

- fast, convenient online submission

- thorough peer review by experienced researchers in your field

- rapid publication on acceptance

- support for research data, including large and complex data types

- gold Open Access which fosters wider collaboration and increased citations

- maximum visibility for your research: over $100 \mathrm{M}$ website views per year

At $\mathrm{BMC}$, research is always in progress.

Learn more biomedcentral.com/submissions 